\title{
Mesenchymal phosphaturic tumour: early detection of recurrence
}

\author{
Fabiana Allevi, ${ }^{1}$ Dimitri Rabbiosi, ${ }^{2}$ Marco Mandalà, ${ }^{3}$ Giacomo Colletti ${ }^{2}$
}

${ }^{1}$ Department of Maxillofacial Surgery, Università degli Studi di Milano, Milan, Italy

${ }^{2}$ Ospedale San Paolo, Milan, Italy

${ }^{3}$ Azienda Ospedaliera Universitaria Verona, Verona, Italy

Correspondence to Dr Giacomo Colletti, giacomo.colletti@gmail.com

Accepted 4 April 2014

CrossMark

To cite: Allevi $F$, Rabbiosi D, Mandalà M, et al. BMJ Case Rep Published online: [please include Day Month Year] doi:10.1136/bcr-2013202827

\section{SUMMARY}

The case of a recurrent phosphaturic mesenchymal tumour of the maxillary sinus 10 years after the first surgical excision is reported. The neoplasm first presented with paraneoplastic osteomalacia causing a pathological femur fracture. A right maxillary sinus tumour was identified and treated thereafter. The patient had no local symptoms and serum electrolytes returned to normal after surgical removal of the tumour. However, 10 years later, the patient's urine $C a$ and $P$ levels increased and an octreoscan detected a new tumour in the right maxillary sinus. Early diagnosis prevented the effects of the paraneoplastic activity of the neoplasm. This case emphasises the importance of specific, close follow-up, because the neoplasm rarely produces local signs indicating its position. To our knowledge, this is the first reported case of a late relapse presenting without relevant symptoms (local pain or swelling or pathological fractures).

\section{BACKGROUND}

Oncogenic osteomalacia, first described in 1959, is a rare paraneoplastic syndrome usually associated with prostatic and lung neoplasms. ${ }^{1}$ The syndrome is caused by the release of a peptide hormone-like substance, known as fibroblast growth factor 23 (FGF23), which acts on the kidney causing renal phosphate loss with hypophosphataemia. This syndrome is seldom the first manifestation of mesenchymal tumours of the head and neck region. ${ }^{2}$ This type of neoplasm, particularly when arising in a paranasal sinus, grows slowly and starts causing local symptoms and signs only after it has reached a considerable size (more than 25-30 mm). ${ }^{3}$ Osteomalacia, rickets, hyperphosphaturia and hypophosphataemia are usually the first manifestations of the primary tumour, as a consequence of the release of FGF23 into the blood. Neoplasms associated with these functional disorders are usually benign mesenchymal tumours. However, in 2001, Ogose et al reported a case of a recurrent malignant variant of phosphaturic mesenchymal neoplasm behaving like a high-grade sarcoma that presented with oncogenic osteomalacia and soft tissue metastases. ${ }^{4}$ In 2009, Uramoto et al described the case of a patient with a recurrent malignant phosphaturic mesenchymal tumour (PMT) of the tongue. ${ }^{5}$ These lesions have to be resected with wide surgical margins to ensure radical removal. Early diagnosis is essential so that the mass can be easily removed and osteomalacia prevented or treated; systemic symptoms resolve upon radical removal of the mass. Our patient presented with a PMT relapse without symptoms of oncogenic osteomalacia, most probably due to the very early diagnosis of the condition.

\section{CASE PRESENTATION}

Over 10 years ago, the patient presented with a right maxillary sinus mass, discovered after investigation for a paraneoplastic syndrome presenting with oncogenic osteomalacia. She was otherwise healthy, with no family history of neoplastic conditions or bone metabolic diseases. The tumour was removed and 3 weeks later serum and urine $\mathrm{Ca}$ and $P$ levels returned to normal and low blood levels of 1,25 dihydroxyl vitamin $\mathrm{D}$ increased. The patient underwent close clinical and radiographic follow-up and showed no signs of recurrence during the following 10 years. However, urine and serum $\mathrm{Ca}$ and $\mathrm{P}$ levels then deviated from normal: serum levels decreased, while urine levels increased. In addition, 1,25 dihydroxyl vitamin D levels fell below normal. The patient underwent an octreotide scan that showed a pathological maxillary concentration of the radiotracer (figure 1) that led to an incisional biopsy of the mass (figure 2). Histology revealed the same features as the first specimen: a mesenchymal phosphaturic neoplasm with a hemangiopericytoma-like vascular pattern. The patient underwent a second surgical procedure with radical removal of the mass. Three weeks after surgery her serum and urine levels had returned to normal. The patient has not shown any signs of

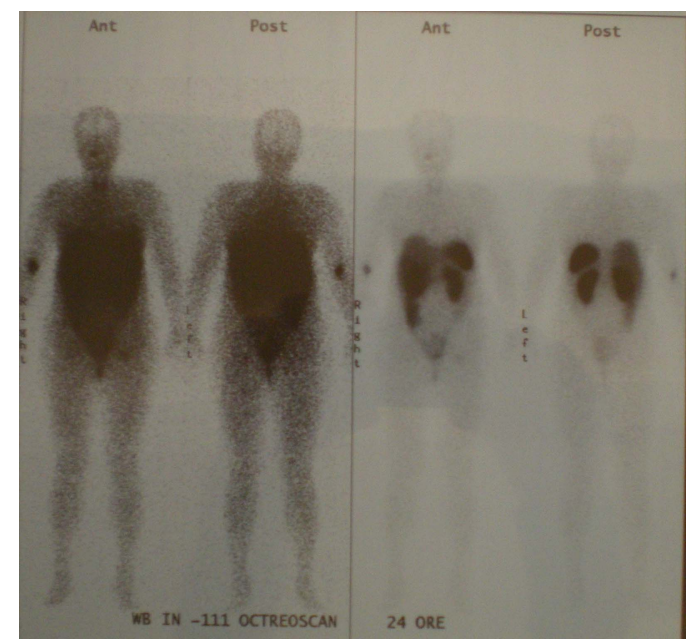

Figure 1 Octreoscan showing increased radiotracer uptake in the right maxillary sinus corresponding to tumour recurrence. 


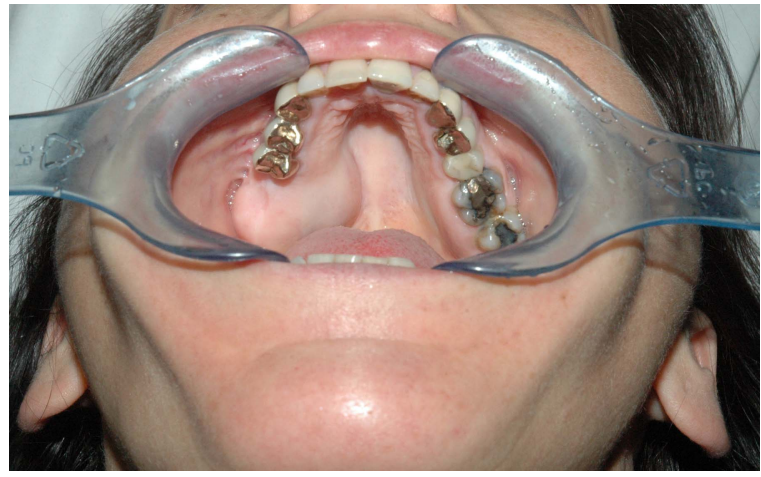

Figure 2 Pre-operative photograph showing the tumour located in the right maxillary bone.

local recurrence during a 4-year follow-up period (figure 3).

\section{INVESTIGATIONS}

Bone and muscle pain are often the first clinical symptoms of PMTs; pain usually appears only after the tumour has reached a considerable size. Patients usually undergo multiple imaging and laboratory examinations before the mass responsible for the skeletal symptomatology is identified: X-rays show bone rarefaction areas suggesting osteomalacia, while laboratory examinations typically identify abnormal serum and urine $\mathrm{Ca}$ and P levels. Phosphaturia, hypercalciuria, hypocalcaemia and hypophosphataemia are specific features of osteomalacia. Before a possible differential diagnosis of paraneoplastic-induced osteomalacia is investigated, parathyroid hormone (PTH), 25-hydroxyl vitamin D and 1,25-dihydroxyl vitamin D levels should be evaluated in order to rule out more common causes of osteomalacia such as renal failure and inappropriate vitamin D intake. Consistently with other patients with paraneoplastic osteomalacia, in this case PTH and 25-hydroxyl vitamin D levels were normal both in the presence of the primary tumour (42 pg/mL (42 ng/L) and $51 \mathrm{ng} / \mathrm{mL}(127.3 \mathrm{nmol} / \mathrm{L})$, respectively) and during recurrence $(47 \mathrm{pg} / \mathrm{mL}(47 \mathrm{ng} / \mathrm{L})$ and $49 \mathrm{ng} / \mathrm{mL}$ (122.3 nmol/L), respectively), while 1,25-dihydroxyl vitamin D levels were below normal in both cases $(7$ and $12 \mathrm{pg} / \mathrm{mL}(18.2$ and $31.2 \mathrm{pmol} / \mathrm{L}$ ), respectively). This feature is due to vitamin $\mathrm{D}$ 1-hydroxylation inhibition caused by FGF23 hyperproduction.

Since various neoplastic condition can induce paraneoplastic osteomalacia, an octreoscan might be helpful in the general diagnostic investigation. The octreoscan is able to rule out a

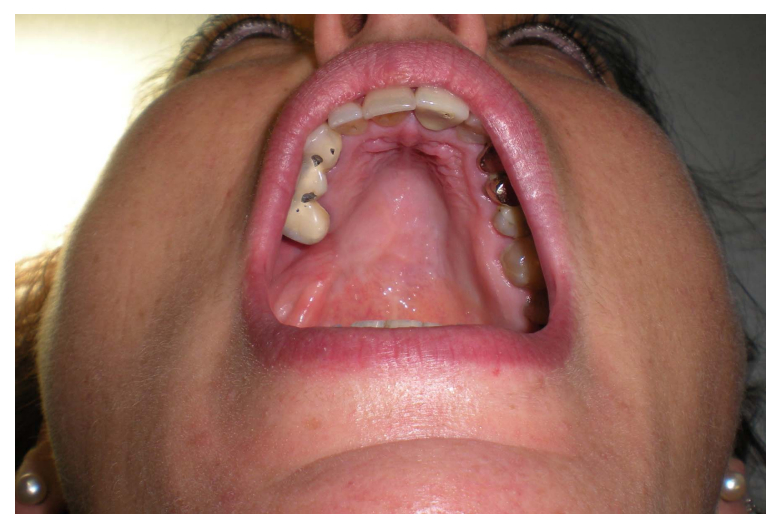

Figure 3 Post-operative photograph showing no signs of local recurrence. paraneoplastic syndrome-inducing neoplasm or to identify its location based upon its uptake of octreotide, a radiotracer intensely internalised by cells with endocrine activity. ${ }^{6}$

Takeuchi and colleagues reported the case of a patient with tumour-induced osteomalacia due to the production of FGF23. ${ }^{7}$ Before surgery, they confirmed the diagnosis using venous sampling of FGF23; serum levels of FGF23 are normal in about 3\% of patients with a diagnosis of tumour-induced osteomalacia. However, most laboratories do not test for FGF23 on a routine basis and the assay lacks standardisation, reducing the significance of the results. Therefore, we did not investigate FGF23 levels in our patient. In this case, the octreoscan showed increased radiotracer uptake in the right maxillary sinus, so the patient underwent contrast-enhanced CT and nuclear magnetic resonance imaging (figure 4) to better define the location and extent of the mass as part of pre-surgical planning. An incisional biopsy was performed before radical excision of the tumour.

\section{DIFFERENTIAL DIAGNOSIS}

The mere existence of PMT as a distinct pathological entity is still ignored by most clinicians and pathologists. When a patient presents with chronic bone and muscle symptoms, one of the first diagnostic steps is to establish whether they are affected by a paraneoplastic syndrome, in which case the clinician has to identify the primary tumour. Many cases are diagnosed as giant cell tumour, hemangiopericytoma, osteosarcoma or other mesenchymal tumours. ${ }^{8} 9$ Histological features usually allow for correct diagnosis.

\section{TREATMENT}

We approached the neoplasm surgically through a combined endonasal and transoral approach. The lesion was completely removed along with the macroscopically infiltrated mucosal and bony (palatal and maxillary) segments. The surgical defect was successfully closed with a buccal fat pad flap. No complications were reported.

\section{OUTCOME AND FOLLOW-UP}

Serum and urine $\mathrm{Ca}$ and $\mathrm{P}$ levels had returned to normal 3 weeks after surgery, and normal levels of 1,25-dihydroxyl vitamin $\mathrm{D}$ were restored. The patient never complained of bone or muscle pain and, after 4 years of follow-up, she is now healthy with no signs of recurrence. Close follow-up is mandatory to ensure early relapses are identified. When the tumour site is not directly visible during physical or endoscopic examination, the most useful follow-up evaluation is long-term serial serum and urine $\mathrm{Ca}$ and $\mathrm{P}$ testing, coupled with head imaging (contrast CT or MR), which, based on our experience, should be performed every 3 months for the first 2 years, then every 6 months for the next 8 years. In case of prolonged and otherwise unexplained bone and muscle pain, both in the tumour site and in distant sites, recurrence should be always be considered in the differential diagnosis.

\section{DISCUSSION}

PMT is a rare, albeit usually benign, neoplasm of mesenchymal origin. Metastasising variants occur extremely rarely. ${ }^{4}$ The term 'phosphaturic' stems from a circulating phosphaturic agent, a peptide hormone-like substance, initially called phosphatonin and then identified as FGF23, that acts on the renal resorption of phosphate, resulting in systemic bone demineralisation and oncogenic osteomalacia. ${ }^{10}$ Often, bony and/or muscular disturbances are the first manifestation of this type of tumour, while local signs become evident only when the mass 
Figure 4 MRI showing the location of the tumour in the right maxillary sinus.

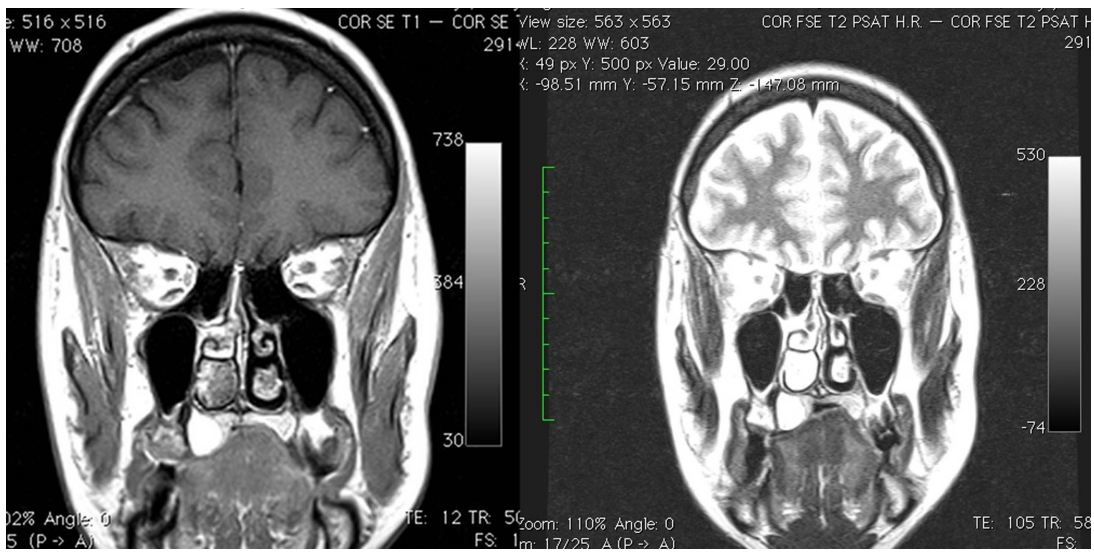

reaches a considerable size. In 1959, Prader reported the first case of tumour-related osteomalacia. ${ }^{1}$ Oncogenic osteomalacia commonly affects male and female adults, peaking in the fourth decade of life. The most common sites include the extremities, neck and head (mandible, paranasal sinuses and nasopharynx).

Histological examination usually shows proliferating spindle cells with low nuclear grade and low mitotic rate encased in a chondromyxoid or osteoid-like matrix with large calcifications.

In 1987, Weidner and Santa Cruz identified four morphological PMT groups: mixed connective tissue variant (the most common), osteoblastoma-like variant, non-ossifying fibroma-like variant and ossifying fibroma-like variant. ${ }^{11}$ The differential diagnosis includes giant cell tumours, hemangiopericytoma, and osteosarcoma or other mesenchymal tumours. ${ }^{8} 9$

In 2004, Folpe et al described three cases of the nonphosphaturic variant of PMT. They proposed two hypotheses to explain the absence of a paraneoplastic syndrome: tumour cells might have produced an inactive form of FGF23 or patients might have been otherwise able to compensate. ${ }^{12}$ In our case, the patient did not develop osteomalacia-related symptoms because the very early diagnosis of the recurrence allowed the mass to be identified before it could cause any symptoms or signs.

The gold standard treatment is radical excision of the tumour, which leads to the resolution of tumour-related osteomalacia. In 2001, Seufert proposed that patients not eligible for surgery

\section{Learning points}

- Always consider paraneoplastic syndromes in the differential diagnosis of unexplained electrolyte imbalances.

- Consider that electrolyte imbalances could be an early sign of recurrence of paraneoplastic syndrome-inducing tumours.

- In case of prolonged and otherwise unexplained bone and muscle pain, both in the tumour site and in distant sites, recurrence should be always be considered in the differential diagnosis.

- Early diagnosis and treatment of paraneoplastic syndrome-inducing tumours can help to prevent the development of major signs and symptoms, with an appreciable impact on the patient's quality of life. could undergo medical treatment with octreotide. He reported the case of a patient who underwent subcutaneous administration of octreotide $(50 \mu \mathrm{g}$ three times a day for 5 days and then $100 \mu \mathrm{g}$ three times a day for 8 days) with resolution of renal dysfunction. ${ }^{13}$ This type of treatment is still controversial: Paglia et $a l^{14}$ tried to manage PMT with octreotide without any positive results. Uramoto proposed radiotherapy as an alternative treatment for the malignant variant if radical resection is not feasible. ${ }^{5}$

Post-operative laboratory and radiographic follow-up is mandatory.

Contributors DR and GC carried out the surgery and MM performed the biopsy. FA wrote the article.

Competing interests None.

Patient consent Obtained.

Provenance and peer review Not commissioned; externally peer reviewed.

\section{REFERENCES}

1 Prader VA, Illig R, Vehlinger $E$, et al. Rachitis infolge, knochen tumors. Helv Pediatr Acta 1959;14:554-65.

2 Pedrazzoli M, Colletti G, Ferrari M, et al. Mesenchymal phosphaturic neoplasm in the maxillary sinus: a case report. Int J Oral Maxillofac Surg 2010;39:1027-32.

3 Kominek P, Starek I, Geierova M, et al. Phosphaturic mesenchymal tumor of the sinonasal area: case report and review of the literature. Head Neck Oncol 2011;16:3-16.

4 Ogose A, Hotta T, Emura I, et al. Recurrent malignant variant of phosphaturic mesenchymal tumor with oncogenic osteomalacia. Skeletal Radiol 2001;30:99-103.

5 Uramoto N, Furukawa M, Yoshizaki T. Malignant phosphaturic mesenchymal tumor, mixed connective tissue variant of the tongue. Auris Nasus Larynx 2009;36:104-5.

6 Rhee Y, Lee JD, Shin KH, et al. Oncogenic osteomalacia associated with mesenchymal tumor detected by indium-111 octreotide scintigraphy. Clin Endocrinol 2001;:54:551-4

7 Takeuchi Y, Suzuki H, Ogura $S$, et al. Venous sampling for fibroblast growth factor-23 confirms preoperative diagnosis of tumor-induced osteomalacia. J Clin Endocrinol Metab 2004;89:3979-82.

8 Chung EB, Enzinger FM. Chondroma of soft parts. Cancer 1978;41:1414-24.

9 Oliveira AM, Dei Tos AP, Fletcher CD, et al. Primary giant cell tumor of soft tissues: a study of 22 cases. Am J Surg Pathol 2000;24:248-56.

10 Sundaram M, McCarthy EF. Oncogenic osteomalacia. Skeletal Radiol 2000:29:117-24

11 Weidner N, Santa Cruz D. Phosphaturic mesenchymal tumors. A polymorphous group causing osteomalacia or rickets. Cancer 1987;59:1442-54.

12 Folpe AL, Fanburg-Smith JC, Billings SD, et al. Most osteomalacia-associated mesenchymal tumors are a single histopathologic entity: an analysis of 32 cases and a comprehensive review of the literature. Am J Surg Pathol 2004;28:1-30.

13 Seufert J, Ebert K, Muller J, et al. Octreotide therapy for tumor-induced osteomalacia. N Engl J Med 2001;345:1883-8.

14 Paglia F, Dionisi S, Minisola S. Octreotide for tumor-induced osteomalacia. N Engl J Med 2002:346:1748-9. 
Copyright 2014 BMJ Publishing Group. All rights reserved. For permission to reuse any of this content visit http://group.bmj.com/group/rights-licensing/permissions.

BMJ Case Report Fellows may re-use this article for personal use and teaching without any further permission.

Become a Fellow of BMJ Case Reports today and you can:

- Submit as many cases as you like

- Enjoy fast sympathetic peer review and rapid publication of accepted articles

- Access all the published articles

- Re-use any of the published material for personal use and teaching without further permission

For information on Institutional Fellowships contact consortiasales@bmjgroup.com

Visit casereports.bmj.com for more articles like this and to become a Fellow 